\title{
Cranial Nerve Foramina Part I: A Review of the Anatomy and Pathology of Cranial Nerve Foramina of the Anterior and Middle Fossa
}

\author{
Bryan Edwards $^{1}$, Joy MH Wang ${ }^{2}$, Joe Iwanaga ${ }^{3}$, Marios Loukas ${ }^{1}$, R. Shane Tubbs ${ }^{4}$ \\ 1. Department of Anatomical Sciences, St. George's University School of Medicine, Grenada, West Indies \\ 2. Department of Anatomical Sciences, St. George's University School of Medicine, Grenada, West Indies \\ 3. Seattle Science Foundation 4. Neurosurgery, Seattle Science Foundation
}

$\square$ Corresponding author: Joy MH Wang, mwang@sgu.edu

Disclosures can be found in Additional Information at the end of the article

\section{Abstract}

Cranial nerve foramina are integral exits from the confines of the skull. Despite their significance in cranial nerve pathologies, there has been no comprehensive anatomical review of these structures. Owing to the extensive nature of this topic, Part I of our review, presented here, focuses on the foramina of the anterior and middle cranial fossae, discussing each foramen's shape, orientation, size, surrounding structures, and structures that traverse them. Furthermore, by comparing the size of each foramen against the cross-sectional areas of its contents, we estimate the amount of free space in each. We also review lesions that can obstruct the foramina and discuss their clinical consequences.

Categories: Miscellaneous, Neurosurgery, Other

Keywords: foramina, cranial nerve, anterior fossa, middle fossa, cribiform plate, sphenoid, superior orbital fissure, optic canal, foramen rotundum, foramen ovale

\section{Introduction And Background}

Cranial nerve foramina are integral exits from the confines of the skull. On their long intracranial journeys and subsequent passage through these skeletal portals, cranial nerves can travel alone or with accompanying vascular structures. The foramina can sometimes become too small, or pathological obstructions (e.g., achondroplasia, fibrous dysplasia, osteopetrosis) can develop and impinge upon them, with potentially severe clinical consequences.

In this review, we describe the anatomy of the cranial nerve foramina of the anterior and middle fossa (highlighted in blue and green, respectively, in Figure 1) in terms of locations within the skull, shapes, dimensions, crucial surrounding structures, and any documented variations. The structures passing through these foramina and their corresponding sizes within them are reviewed by comparing their respective cross-sectional areas. Finally, pathological obstructions of the foramina and impingement of their contents are reviewed, along with the corresponding clinical consequences. To our knowledge, this is the first comprehensive review of the cranial nerve foramina of the anterior and middle fossae.
Received 11/24/2017

Review began 01/26/2018

01/29/2018

@ Copyright 2018

Edwards et al. This is an open access article distributed under the terms of the Creative Commons Attribution License CC-BY 3.0., which permits unrestricted use, distribution, and reproduction in any medium, provided the original author and source are credited.
How to cite this article

Edwards B, Wang J, Iwanaga J, et al. (February 08, 2018) Cranial Nerve Foramina Part I: A Review of the Anatomy and Pathology of Cranial Nerve Foramina of the Anterior and Middle Fossa. Cureus 10(2): e2172. DOI 10.7759/cureus.2172 


\section{Cureus}

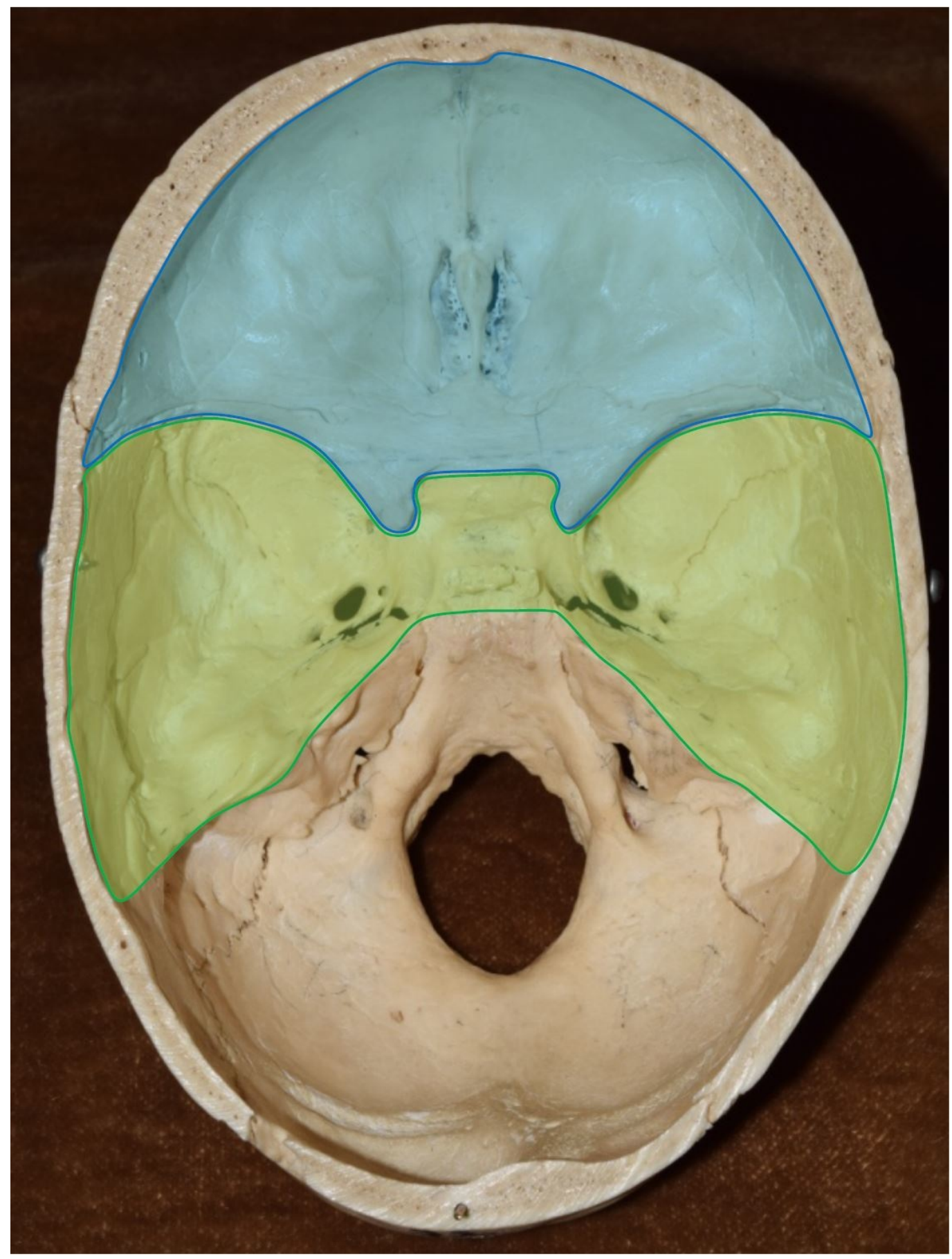

FIGURE 1: Superior view of cranial floor

Blue - Anterior Cranial Fossa; Green - Middle Cranial Fossa

\section{Limitations}

Information regarding structural diameters, sizes of lesions, and measurements of masses extending into these foramina is seldom or never reported in the literature.

\section{Review}




\section{Cureus}

\section{Middle cranial fossa}

Foramen Ovale (FO)

Situated in the posterior aspect of the lesser sphenoid wing and anteromedial to the sphenoid spine, the foramen ovale (Figure 2) adopts various shapes including oval, almond, round, and slit [1-2]. The predominant shape is oval, with dimensions ranging from $5 \times 2 \mathrm{~mm}$ to $8 \times 7 \mathrm{~mm}$,

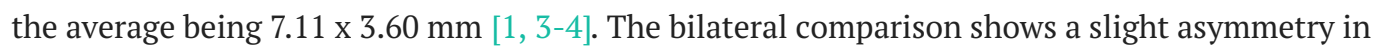
the cross-sectional area, the right being $16.55 \mathrm{~mm}^{2}$ and the left $14.39 \mathrm{~mm}^{2}$. As with other foramina, ossification can divide it into two separate compartments; a full division has been reported in $2.8 \%$ of cases and a partial division in $12.8 \%$ [1]. Directly inferior to the exocranial surface of the FO, two ossified ligaments, known as the pterygospinous bar and the pterygoalar bar, are found in some cases. The prevalence of the pterygospinous bar, also known as the ligament of Civinini, has been reported as 2.6 - 17\%, while that of the pterygoalar bar, also known as the ligament of Hyrtl, has been reported as 2.6 - 30\% [5-6]. These bars can be unilateral and/or extend additionally over the foramen spinosum [7].

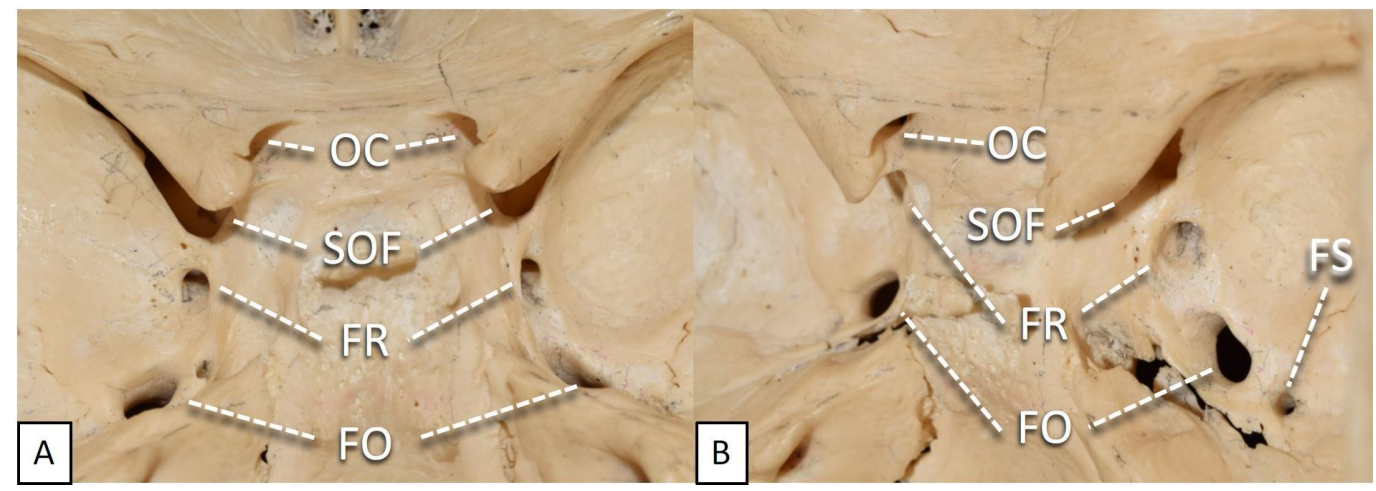

FIGURE 2: Close-up view of cranial nerve foramina within middle cranial fossa

A: Superior view; B: Oblique view.

OC: optic canal; SOF: superior orbital fissure; FR: foramen rotundum; FO: foramen ovale; FS: foramen spinosum.

Surrounding this foramen are several important landmarks and structures. Medial to the FO, but lateral to the sella turcica, lies the cavernous sinus with its own important structures. Three millimeters posterolaterally lies the foramen spinosum, which contains the middle meningeal artery and the recurrent branch of the mandibular nerve. The carotid artery runs directly posterior to the intracranial opening of the foramen. The foramen rotundum lies $8-10 \mathrm{~mm}$ anteromedially and holds the maxillary branch of the trigeminal nerve [8]. Directly superior to it are the temporal lobes and the heart of the trigeminal nerve within Meckel's cave [9]. Inferior to it is the intratemporal fossa. The posterior clinoid process is located $26.1 \mathrm{~mm}$ superolaterally.

The main structure running through the FO is the mandibular branch (V3) of the trigeminal nerve. Other structures include the accessory branch of the middle meningeal artery, the lesser petrosal nerve, small emissary veins, and the middle meningeal artery [7, 10]. The venous plexus, joining the cavernous sinus to the pterygoid plexus, can also run through this path [11]. If we compare the cross-sectional area of the mandibular nerve, $7.8-14.5 \mathrm{~mm}^{2}$ on the right and 
$10.4-16.2 \mathrm{~mm}^{2}$ on the left [12], with that of the foramen, $16.55 \mathrm{~mm}^{2}$ on the right and 14.39 $\mathrm{mm}^{2}$ on the left [7], it is clear that lesions can potentially obstruct the FO.

Extrinsic carcinomas appear to be the main cause of FO obstruction with clinical consequences. Laine et al. described three patients who had FO obstructions secondary to an adenoid cystic carcinoma traveling medially into the foramen [9]. Some of these patients presented only with the sensation of an enlarged mass on the side of their face, while others reported facial pain and displayed signs of masticator atrophy and cavernous sinus syndrome - a paresis of the oculomotor, trochlear, and abducens nerves. Obstruction by a squamous cell carcinoma has also been reported. Laine et al. reported several cases of FO obstruction secondary to squamous cell carcinoma, in which squamous cells from the maxillary sinus traveled deep into the skull via the trigeminal nerve, entering the FO, the superior orbital fissure, and the pterygoid fossa [9]. These patients experienced a combination of facial pain, chronic nasal discharge, and atrophied muscles of mastication. Barakos et al. reported a squamous cell carcinoma that spread from the lower facial region to the FO perineurally. The patient suffered progressive dysesthesia on the right side of the face along the distribution of the mandibular nerve [10]. Non-Hodgkins lymphoma originating from the orbit has also been shown to invade the FO and cavernous sinus; similarly, non-Hodgkins lymphoma originating from within the cranial cavity has been documented to extend through the FO along the mandibular branch [13].

The FO is therapeutically important as an access to Meckel's cave in procedures, such as radiofrequency trigeminal rhizotomy and balloon compression, used to alleviate symptoms of trigeminal neuralgia. However, anatomical variations should be kept in mind, as Tubbs et al. reported cases of elongated or enlarged sphenoid spines that can obstruct and prevent glycerol rhizolysis [5]. Anatomical variations of the ligaments of Civinini and Hyrtle can also have clinical implications; if they compress the branches of the mandibular nerve, mastication weakness and sensory loss can result [6].

\section{Foramen Rotundum (FR)}

As the gateway for the maxillary branch of the trigeminal nerve, the foramen rotundum (Figure 2) sits vertically in the anteromedial portion of the greater sphenoid wing. It is posteroinferior to the medial edge of the superior orbital fissure, lateral to the anterior aspect of the sella turcica, inferior to the anterior clinoid process, and superior to the sphenoid bone and continuing nasal cavity. The foramen itself is circular with an average diameter of $3.9 \times 3.13$ $\mathrm{mm}$ [4], the left being slightly wider than the right [3]. In $1 \%$ of skulls, an accessory canal originates from the lateral wall of the FR and travels superiorly and diagonally to the orbit; its diameter and length have been measured as $0.2-1.0 \mathrm{~mm}$ and $5.0 \mathrm{~mm}$, respectively [14-15]. The cross-sectional area of the FR is $9.48 \mathrm{~mm}^{2}$ and $9.45 \mathrm{~mm}^{2}$ on the right and left, respectively [16]. Interestingly, although the dimensions of the right and left sides are nearly identical, Neto et al. found a greater incidence of trigeminal neuralgia on the right [17]. In view of the wide-ranging cross-sectional area of the maxillary nerve $\left(6.2-15.3 \mathrm{~mm}^{2}\right.$ on the right and $4.6-15.3 \mathrm{~mm}^{2}$ on the left) [12], the amount of free space is highly variable so the fit can be tight, easily allowing a mass to impinge on the nerve within the foramen.

Hedeman et al. reported a case in which a malignant schwannoma in the heart of the trigeminal ganglion, also known as the Gasserian ganglion, protruded into the FR, causing right-sided pain and a burning sensation along the distribution of the maxillary nerve [18]. A 5 $\mathrm{cm}$ non-Hodgkins lymphoma originating from the parotid gland invaded the FR of a 17-monthold girl presenting with face and neck masses.

Superior Orbital Fissure (SOF) 
Sitting in the sphenoid bone, the superior orbital fissure (Figure 2) comprises several parts: its superior and inferior borders are the lesser and greater wings of the sphenoid, respectively; its medial inferior edge is composed of the body of the sphenoid; and a small portion of the lateral aspect is contributed by the frontal bone. Superomedial to the SOF is the optic canal, separated by the optic strut; behind this structure runs the intracranial portion of the carotid artery. The

FR, transmitting the maxillary branch of the trigeminal nerve, lies directly inferior to the medial base of the SOF. Posteriorly is the cavernous sinus, which lies lateral to the sella turcica.

Attached to the medial side is the annular tendon, which gives rise to the extraocular muscles. The tendons of these muscles divide the fissure into three compartments: 1) the lateral sector (formed by the tendons of the lateral rectus and the lateral border of the SOF) containing the trochlear nerve, the frontal and lacrimal nerves (branches of V1), and the superior ophthalmic vein (listed lateral to medial); 2) the central sector (formed by the tendons of the inferior and lateral rectus) containing the oculomotor, nasocilliary (branch of V1), and abducens nerves and roots from the ciliary ganglion; and 3) the inferior sector (formed by the tendons of the inferior rectus and medial border of the SOF) containing the inferior ophthalmic vein, orbital fat, and smooth muscle [19].

The length of the fissure ranges from 20.05 - $22.0 \mathrm{~mm}[4,20]$, with apical and basal widths of 2 $3 \mathrm{~mm}$ and $7-8 \mathrm{~mm}$, respectively [20]. Owing to its odd shape, the cross-sectional areas of the SOF and its passing structures have not been well documented. One study reported that the trochlear nerve has an average diameter of $0.54 \mathrm{~mm}$ [21]. Using the formula for the area of a circle, we calculate the cross-sectional area of the trochlear nerve to be $0.23 \mathrm{~mm}^{2}$. Clinically, obstructions at the SOF can have significant detrimental effects on vision.

A condition known as SOF syndrome (SOFS) is caused by the compression or obstruction of the structures passing through the SOF; it typically presents with a mixture of signs and symptoms, including ipsilateral unreactive pupil, ptosis, proptosis, ophthalmoplegia, and anesthesia of the upper eyelid and forehead [22-23]. Trauma and fractures appear to be the culprits in most of these cases. Rai et al. and Evans et al. reported several cases of direct fractures of the lateral wall of the orbit and indirect compression of the SOF secondary to zygomaticomaxillary fractures [20, 22]. They resulted in ophthalmoplegia, ptosis, proptosis, numbness over the forehead, dilated pupils, loss of corneal and direct light reflex, while the consensual light reflex remained intact, and loss of accommodation with no evidence of optic nerve injury [20]. The lateral wall of the orbit can also be affected by a frontosphenotemporal fracture, leading to impingement on the structures within the SOF [24]. Carcinoma can also cause SOFS. Kleydman et al. reported a case in which a basal cell carcinoma of the left nasal ala retrogradely invaded the orbit, including the SOF and much of the skull base. Because most of the involvement was around the orbit, the patient experienced bilateral vision loss, tearing, and swelling [25]. Squamous cell carcinomas have also been reported [26]. Infection can also cause compression of these structures. Aspergillus fumigates extending superiorly from the right sphenoid sinus was the reported cause of SOFS in a 60-year-old man presenting with ptosis, ophthalmoplegia, and forehead hypoesthesia [27]. Chronic tertiary syphilis can also have this effect [28].

\section{Optic Canal (OC)}

Allowing passage for the messenger of sight, the optic canal sits in the superior aspect of the sphenoid body and directly transverses outward into the medial wall of the orbit (Figure 2). Directly anterior to the tip of the anterior clinoid process and slightly anteromedial to the sella turcica, the optic canal is the most superiorly situated foramen in the middle fossa. It is anterior to the cavernous sinus, superolateral to the sphenoid sinus, and inferior to the frontal lobes. Anteromedial to the $\mathrm{OC}$ is the ethmoid bone. The triangular area that contains the foraminal openings of the optic canal, along with the ethmoid bone, is called the planum sphenoidale. The prechiasmatic sulcus is the groove on the anterior aspect of the sphenoid body connecting 
the openings of the two canals. The distal end of the OC is narrower than the proximal end [29]; the intracranial and orbital openings having average dimensions of $6.25 \times 3.70 \mathrm{~mm}$ and $4.75 \mathrm{x}$ $5.46 \mathrm{~mm}$, respectively [4]. The canal itself is $8-12 \mathrm{~mm}$ long and is duplicated in $2.57 \%$ of skulls [30].

The optic nerve, with a cross-sectional area of $5.17 \mathrm{~mm}^{2}$ [31], runs through the foramen beside the ophthalmic artery. This artery has a diameter of $0.7-1.8 \mathrm{~mm}$ [32]; using the formula for the area of a circle, we find that its cross-sectional area is $0.38 \mathrm{~mm}^{2}$ to $2.54 \mathrm{~mm}^{2}$. Summing the areas, we obtain 5.55 to $6.97 \mathrm{~mm}^{2}$. Comparing this with the calculated cross-sectional areas of the orbital and intracranial openings, $18.16 \mathrm{~mm}^{2}$ and $20.33 \mathrm{~mm}^{2}$, respectively, we find $11 \mathrm{~mm}^{2}$ of free space. Therefore, a lesion around $1 \mathrm{~cm}$ would be expected to compress the internal structures. As Jackson et al. remarked, small tumors in the canal can produce symptoms but can be difficult to see [33].

Meningiomas, the most common intracranial tumors, involve the orbit in less than $2 \%$ of cases. However, when they do invade the canal, they cause progressive vision loss [34]. The usual patient presentation is a female between 24 and 38 years of age presenting with cloudy vision, decreased visual acuity, loss of color vision, or complete loss of vision, with possible findings of papilledema and pallor discs secondary to ophthalmic artery compression [33, 35]. From the planus sphenoidale, meningotheliomatous meningiomas could also extend posterolaterally into the canals [34]. Meningiomas extending from the tuberculum sella have been shown to invade the OC in $77.4 \%$ of cases, causing vision loss in $84.6 \%$ of those cases [36]. From within the canal itself, the ophthalmic artery can compress the optic nerve. A fusiform, irregular aneurysm of the ophthalmic artery, measuring approximately $4 \times 3 \mathrm{~mm}$ and running the entire length of the canal, was reported in a 53-year-old man presenting with a progressive decrease in visual acuity and color perception [37]. The cross-sectional area of this aneurysm, using the formula for the area of an ellipse, would be $9.41 \mathrm{~mm}^{2}$, which is considerable since less than 11 $\mathrm{mm}^{2}$ of free space is available within the canal. A mucocele involving the left anterior clinoid process and optic strut was reported to compress the optic nerve in the left OC causing headaches, vision loss, and amaurotic pupil with mild impairment of abduction and corneal sensation. Fracture of the lesser wing of the sphenoid and posterior aspect of the ethmoid bone reportedly causes complete infarction of the ophthalmic artery in the canal, either from direct rupture of the artery secondary to the force of the trauma or from indirect compressive forces secondary to subsequent swelling and edema [38]. Fibrous dysplasia can also lead to optic nerve compression. Of the 93 patients studied, Tan et al. reported that 18 had evidence of OC involvement, 14 of whom suffered symptoms of complete blindness, loss of certain visual fields, or loss of color vision [35]. Additionally, osteopetrosis has been associated with stenosis of the optic canal with optic nerve atrophy [39].

\section{Anterior compartment}

Foramina of the Cribriform Plate

The cribriform plate is the gateway to the nasal passages from inside the skull (Figure 3). It is interposed between the frontal and sphenoid bones. It lies horizontally with multiple foramina less than $1 \mathrm{~mm}$ in diameter perforating through it [40]. The olfactory bulb sits directly superior to it, transmitting the olfactory nerves from the nasal mucosa below. The total area of the perforations is age-dependent; it is $3.79-3.99 \mathrm{~mm}^{2}$ in those over 50 years old and $5.61-7.91$ $\mathrm{mm}^{2}$ in those under 50 . This decrease in the area over time, causing compression and dysfunction of the olfactory nerves, is thought to explain the decreased olfactory sensation in the elderly [41]. 


\section{Cureus}

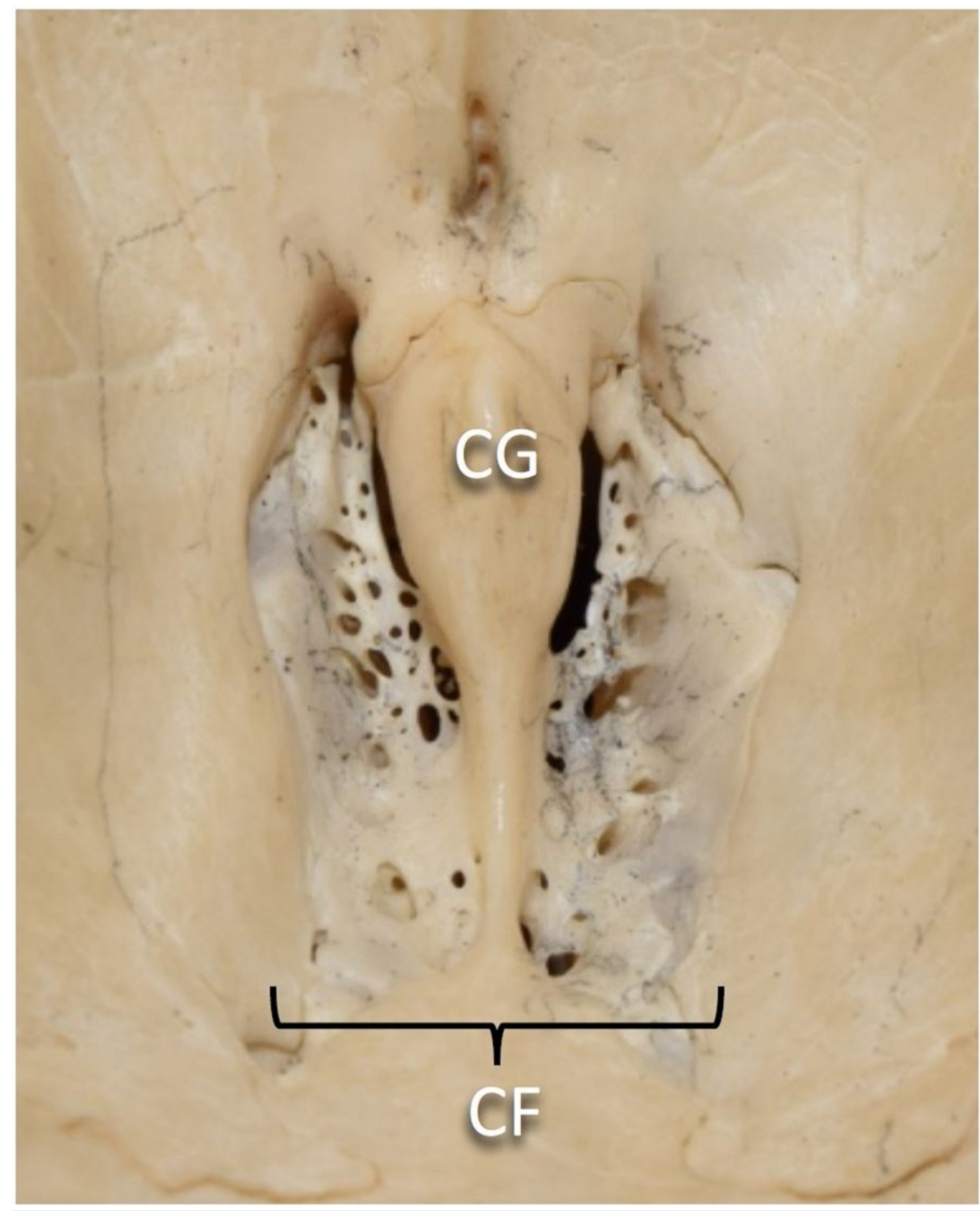

FIGURE 3: Close-up view of cranial nerve foramina within anterior cranial fossa

CG: crista galli; CF: cribriform plate

Clinically, most lesions affecting the foramina of the cribriform plate are schwannomas and meningiomas near the olfactory groove, causing headaches, seizures, personality changes (due to the proximity to the frontal lobes), and visual field defects (due to the proximity of the optic chiasm) [42-45]. Interestingly, anosmia is typically not a complaint and is only noted in hindsight [44]. This could be attributed to the slow rate of growth of these tumors.

\section{Conclusions}

This review has examined the cranial nerve foramina of the anterior and middle fossae. When 
their dimensions are compared with the size of their contents, we can estimate the free space available; it is evident that lesions do not have to be large to cause impingement and significant clinical consequences. Understanding of these osseous defects is important for many disciplines in clinical medicine and surgery. We hope this review elucidates the spatial anatomy and various pathologies of the anterior and middle fossa foramina.

\section{Additional Information \\ Disclosures}

Conflicts of interest: In compliance with the ICMJE uniform disclosure form, all authors declare the following: Payment/services info: All authors have declared that no financial support was received from any organization for the submitted work. Financial relationships: All authors have declared that they have no financial relationships at present or within the previous three years with any organizations that might have an interest in the submitted work. Other relationships: All authors have declared that there are no other relationships or activities that could appear to have influenced the submitted work.

\section{References}

1. Ray B, Gupta N, Ghose S: Anatomic variations of foramen ovale . Kathmandu Univ Med J (KUMJ). 2005, 3:64-68.

2. Tubbs RS, Kicielinski KP, Cure J, et al.: An anatomic variant causing a previously unreported complication of transcutaneous treatment of trigeminal neuralgia. Ital J Anat Embryol. 2016, 121:179-83. 10.13128/IJAE-18492

3. Berge JK, Bergman RA: Variations in size and in symmetry of foramina of the human skull . Clin Anat. 2001, 14:406-13. 10.1002/ca.1075

4. Berlis A, Putz R, Schumacher M: Direct and CT measurements of canals and foramina of the skull base. Br J Radiol. 1992, 65:653-61. 10.1259/0007-1285-65-776-653

5. Tubbs RS, May WR, Apaydin N, et al.: Ossification of ligaments near the foramen ovale: an anatomic study with potential clinical significance regarding transcutaneous approaches to the skull base. Neurosurgery. 2009, 65:60-64. 10.1227/01.NEU.0000345952.64041.9C

6. Kamath KB, Vasantha K: Anatomical study of pterygospinous and pterygoalar bar in human skulls with their phylogeny and clinical significance. J Clin Diagn Res. 2014, 8:AC10-13. 10.7860/JCDR/2014/9326.4888

7. Zdilla MJ, Hatfield SA, McLean KA, et al.: Circularity, solidity, axes of a best fit ellipse, aspect ratio, and roundness of the foramen ovale: a morphometric analysis with neurosurgical considerations. J Craniofac Surg. 2016, 27:222-28. 10.1097/SCS.0000000000002285

8. Kaplan M, Erol FS, Ozveren MF, et al.: Review of complications due to foramen ovale puncture. J Clin Neurosci. 2007, 14:563-68. 10.1016/j.jocn.2005.11.043

9. Laine FJ, Braun IF, Jensen ME, et al.: Perineural tumor extension through the foramen ovale: evaluation with MR imaging. Radiology. 1990, 174:65-71. 10.1148/radiology.174.1.2152985

10. Barakos JA, Dillon WP: Lesions of the foramen ovale: CT-guided fine-needle aspiration . Radiology. 1992, 182:573-75. 10.1148/radiology.182.2.1732985

11. Natis K, Repousi E, Sofidis G, Piagkou M: The osseous structures in the infratemporal fossa: foramen ovale, bony spurs, ossified ligaments and their contribution to the trigeminal neuralgia. Acta Neurochir (Wien). 2015, 157:101-103. 10.1007/s00701-014-2197-3

12. Lang J: Clinical Anatomy of the Head: Neurocranium, Orbit, Craniocervical Regions . Lang J (ed): Springer-Verlag, Berlin, Germany; 1983. 10.1007/978-3-642-68242-1

13. Hafner JW, Costello TH, Stocks MS, et al.: Childhood primary parotid non-Hodgkin's iymphoma with direct intracranial extension: A case report. Ear Nose Throat J. 2004, 83:82830.

14. Bertelli E, Regoli M: Branching of the foramen rotundum. A rare variation of the sphenoid . Ital J Anat Embryol. 2014, 119:148-52. 10.13128/IJAE-15141

15. Regoli M, Bertelli E: The revised anatomy of the canals connecting the orbit with the cranial cavity. Orbit. 2017, 36:110-117. 10.1080/01676830.2017.1279662

16. Inal M, Muluk NB, Arikan OK, Sahin S: Is there a relationship between optic canal, foramen 
rotundum, and vidian canal?. J Craniofac Surg. 2015, 26:1382-88.

10.1097/SCS.0000000000001597

17. Neto HS, Camilli JA, Marques MJ: Trigeminal neuralgia is caused by maxillary and mandibular nerve entrapment: Greater incidence of right-sided facial symptoms is due to the foramen rotundum and foramen ovale being narrower on the right side of the cranium. Med Hypotheses. 2005, 65:1179-82. 10.1016/j.mehy.2005.06.012

18. Hedeman LS, Lewinsky BS, Kochridge GK, Trevor R: Primary malignant schwannoma of the Gasserian ganglion. J Neurosurg. 1978, 48:279-83. 10.3171/jns.1978.48.2.0279

19. Natori Y, Rhoton AL Jr: Microsurgical anatomy of the superior orbital fissure . Neurosurgery. 1995, 36:762-75. 10.1227/00006123-199504000-00018

20. Rai S, Rattan V: Traumatic superior orbital fissure syndrome: Review of literature and report of three cases. Natl J Maxillofac Surg. 2012, 3:222-25. 10.4103/0975-5950.111392

21. Choi BS, Kim JH, Jung C, Hwang JM: High-resolution 3D MR imaging of the trochlear nerve . AJNR Am J Neuroradiol. 2010, 31:1076-79. 10.3174/ajnr.A1992

22. Evans HH, Wurth BA, Penna KJ: Superior orbital fissure syndrome: a case report . Craniomaxillofac Trauma Reconstr. 2012, 5:115-20. 10.1055/s-0032-1313363

23. Jensen H, Thomsen ST, Hansen SS, et al.: Superior orbital fissure syndrome and ophthalmoplegia caused by varicella zoster virus with no skin eruption in a patient treated with tumor necrosis alpha inhibitor. Case Rep Neurol. 2015, 7:221-26. 10.1159/000441325

24. Caldarelli C, Benech R, Iaquinta C: Superior orbital fissure syndrome in lateral orbital wall fracture: management and classification update. Craniomaxillofac Trauma Reconstr. 2016, 9:277-83. 10.1055/s-0036-1584392

25. Kleydman Y, Manolidis S, Ratner D: Basal cell carcinoma with intracranial invasion. J Am Acad Dermatol. 2009, 60:1045-49. 10.1016/j.jaad.2008.10.005

26. de Keizer RJ, Padberg GW, de Wolff-Rouendaal D: Superior orbital fissure syndrome caused by intraorbital spread of a cutaneous squamous cell carcinoma and not detected on computed tomography and magnetic resonance imaging. Jpn J Ophthalmol. 1997, 41:104-10. 10.1016/S0021-5155(97)00003-8

27. Bikhazi NB, Sloan SH: Superior orbital fissure syndrome caused by indolent Aspergillus sphenoid sinusitis. Otolaryngol Head Neck Surg. 1998, 118:102-104. 10.1016/S01945998\%2898\%2970383-3

28. Bikhazi NB, Sloan SH: Chronic syphilitic meningitis resulting in superior orbital fissure syndrome and posterior fossa gumma. A report of two cases followed for 20 years. J Clin Neuroophthalmol. 1988, 8:145-59.

29. Maniscalco JE, Habal MB: Microanatomy of the optic canal. J Neurosurg. 1978, 48:402-406. 10.3171/jns.1978.48.3.0402

30. Ghai R, Sinha P, Rajguru J, et al.: Duplication of optic canal in human skulls . J Anat Soc India. 2012, 61:33-36. 10.1016/S0003-2778(12)80009-8

31. Repka MX, Quigley HA: The effect of age on normal human optic nerve fiber number and diameter. Ophthalmology. 1989, 96:26-32. 10.1016/S0161-6420(89)32928-9

32. Michalinos A, Zogana S, Kotsiomitis E, et al.: Anatomy of the ophthalmic artery: a review concerning its modern surgical and clinical applications. Anat Res Int. 2015, 2015:591961. 10.1155/2015/591961

33. Jackson A, Patankar T, Laitt RD: Intracanalicular optic nerve meningioma: a serious diagnostic pitfall. AJNR Am J Neuroradiol. 2003, 24:1167-70.

34. Trobe JD, Glaser JS, Post JD, Page LK: Bilateral optic canal meningiomas: a case report . Neurosurgery. 1978, 3:68-74. 10.1097/00006123-197807000-00012

35. Tan YC, Yu CC, Chang CN, et al.: Optic nerve compression in craniofacial fibrous dysplasia: the role and indications for decompression. Plast Reconstr Surg. 2007, 120:1957-62. 10.1097/01.prs.0000287338.28018.c7

36. Sade B, Lee JH: High incidence of optic canal involvement in tuberculum sellae meningiomas: rationale for aggressive skull base approach. Surg Neurol. 2009, 72:118-23.

10.1016/j.surneu.2008.08.007

37. Piché SL, Haw CS, Redekop GJ, Heran MKS: Rare intracanalicular ophthalmic aneurysm: endovascular treatment and review of the literature. AJNR Am J Neuroradiol. 2005, 26:192931.

38. Ramsay JH: Optic nerve injury in fracture of the canal . Br J Ophthalmol. 1979, 63:607-10. 10.1136/bjo.63.9.607 


\section{Cureus}

39. Curé JK, Key LL, Goltra DD, VanTassel P: Cranial MR imaging of osteopetrosis . AJNR Am J Neuroradiol. 2000, 21:1110-15.

40. Abolmaali N, Gudziol V, Hummel T: Pathology of the olfactory nerve. Neuroimag Clin N Am. 2008, 18:233-42. 10.1016/j.nic.2007.10.002

41. Kalmey JK, Thewissen JGM, Dluzen DE: Age-related size reduction of foramina in the cribriform plate. Anat Rec. 1998, 251:326-29. 10.1002/(SICI)1097-

0185(199807)251:3<326::AID-AR7>3.0.CO;2-T

42. Hussain Saheb S, Mavishetter GF, Thomas ST, et al.: A morphometric study of the jugular foramen in human adult skulls of south India. J Biomed Sci Res. 2010, 2:240-43.

43. Praharaj SS, Vajramani GV, Santosh V, Shankar SK, Kolluri S: Solitary olfactory groove schwannoma: case report with review of the literature. Clin Neurol Neurosurg. 1999, 101:2628.

44. Hentschel SJ, DeMonte F: Olfactory groove meningiomas. Neurosurg Focus. 2003, 14:e4. 10.3171/foc.2003.14.6.4

45. Murakami M, Tsukahara T, Hatano T, et al.: Olfactory groove schwannoma--case report . Neurol Med Chir (Tokyo). 2004, 44:191-94. 10.2176/nmc.44.191 